Corresponding Author: R.A.

Drozdov; email:

roman.drozdov.15@yandex.ru

Dates

Published 13 January 2022

Publishing services provided by

Knowledge E

(c) R.A. Drozdov et al.. This article is distributed under the terms of the Creative Commons

Attribution License, which

permits unrestricted use and

redistribution provided that the

original author and source are credited.

Selection and Peer-review unde the responsibility of the 8th Scientific and Practical Conference Conference Committee.

\section{Biotechnological Aspects of Dietary Fiber Use in the Production of Fermented Dairy Products}

\author{
R.A. Drozdov ${ }^{1}$, M.A. Kozhukhova ${ }^{1}$, T.V. Barkhatova ${ }^{1}$, A.A. Kushnereva ${ }^{2}$, and T.A \\ Drozdova ${ }^{1}$ \\ 1 Federal State Budgetary Educational Institution of Higher Education "The Kuban State \\ Technological University", Krasnodar, Russia \\ ${ }^{2}$ Federal State Budgetary Educational Institution of Higher Education "The Kuban State Medical \\ University" of the Ministry of Healthcare of the Russian Federation, Krasnodar, Russia \\ ORCID
}

R.A. Drozdov; 0000-0002-4948-5120

Abstract. This article presents research results of the chemical composition, physical and chemical properties and biotechnological potential of dietary fiber concentrates (DFCs) obtained from secondary raw materials for the production of carrot and pumpkin juices.It has been established that DFCs, along with dietary fibers (cellulose, hemicellulose, pectin, lignin), contain soluble sugars, nitrogenous substances and carotenoids, which determine their physiological activity and technological properties when used in dairy products fermented with probiotics.The effect of DFCs on the fermentation kinetics of dairy-vegetable mixtures with a starter containing lacto-, bifidobacteria and propionic acid microorganisms was studied. The optimal concentration and the degree of dispersion of carrot and pumpkin DFCs was determined. The findings can be used to ensureoptimal intensification of the fermentation process and the production of probiotic fermented milk drinks with a pleasant taste.

Keywords: dietary fiber, secondary raw materials, functional dairy products, prebiotics, probiotics, enzyme kinetics, probiotic drinks

\section{Introduction}

The creation of new types of foods enriched with dietary fibers (DFs) is one of the priority areas of scientific research, since these products, when consumed regularly, have an antitoxic effect on the human body and help to prevent a number of alimentary diseases: obesity, large intestine diseases, diabetes, atherosclerosis, coronary heart disease and others [1,2].

DFs mainly include substances that form the cell walls of plants and are a complex formed from insoluble cellulose, soluble polysaccharides (pectin, inulin, hemicellulose) and lignin.It is proposed to use secondary raw material resources (SRR) for processing plant raw materials as DFs sources[3].A significant amount of SRR (up to 40\%) is 
formed while producing fruit and vegetable juices.In most cases, they do not find further application in industry, therefore, they can serve as an inexpensive and readily available raw material inDFs production.It has been established that the advantages of DFs obtained from fruit and vegetables are high water-retention, swelling properties, resistance to bile acids, ion-exchange and gel-forming properties, the availability of related biologically active substances: antioxidants, vitamins, mineral elements.[4].Some DFs have prebiotic properties, that is, they are able to have a positive effect on the body through selective stimulation of growth or metabolic activity of normal intestinal microflora.It has been shown that concentrates DFs (DFCs), obtained from SRR fruit and vegetables processing, in some cases show a higher prebiotic activity in comparison with purified commercial preparations [5].

An effective technological method that allows realizing both the physiological and technological potential of DFCs is the use of these ingredients in the composition of probiotic fermented milk products, which significantly expands their positive action spectrum.Such products are easily digested, while normalizing metabolism, helping to improve digestion, the formation of a healthy intestinallining, strengthen immunity, saturate the body with vitamins and minerals, especially calcium [3].

Recently, the researchers' attention has been drawn to DFCs study in fermented milk products quality, their influence on the rheological properties, as well as on the processes of milk fermentation by probiotic cultures. The synergism of dairy and plant components action in the formation of yoghurt consistencyhas been revealed [6].It has been shown that adding DFCs, obtained from SRR citrus fruit processing, to the milk base activates the growth and increases the probiotic microorganismsstability [7].

The objective of our research work is to study the chemical composition, physicochemical properties and biotechnological potential of DFCs, obtained from SRR carrot and pumpkin processing, when used as functional ingredients in fermented dairy products.

\section{Materials and Methods}

The objects of research were DFCs obtained from SRR, formed during the production of juices from carrot varieties "Nantskaya" and pumpkin varieties "Interes".The choice of objects is due to the scale of industrial processing of these types of raw materials, including for the production of juice products, containing a significant amount of DF, carotenoids and other biologically active compounds. To carry out studies, DFCshave 
beenobtained as follows: vegetables were washed, cleaned of inedible parts, chopped, blanched with live steam for 5 minutes to inactivate their own enzymes, cooled and treatedwith enzymes using "Pectinex Ultra SP-L" (fermentation temperature for carrots$50 \pm 2^{\circ} \mathrm{C}$, for pumpkin $-55 \pm 5^{\circ} \mathrm{C}$ during 70 and 60 minutes respectively), then juice was separated on a laboratory centrifugal juicer "Bosch MES3500".The obtainableSRR (pomace) was collected, dried in "Universal-SD-4" infrared oven at a temperature of 55$58^{\circ} \mathrm{C}$ in the center and on the surface of the product layer until a final moisture content of $7-9 \%$, then crushed to a powdery state.To study fermentationkinetics, the obtainable powders were dispersed on sieves into 3 fractions according to the following sizes: 146-257, 258-369, 370-481 $\mu \mathrm{m}$.

The following research methods were used in this work:

- Weight fraction of solid substances obtaining was carried out on the device "Evlas$2 \mathrm{M}$ " in accordance with the enclosed directions;

- Weight fraction of reducing and total sugar was obtained by the colorimetric method using 3,5-dinitrosalicylic acid on "SF-104" spectrophotometer;

- Polysaccharides weight fraction (DF) - according to A.I. Ermakov[8];

- Nitrogenous substances weight fraction - by the Kjeldahl method [9];

- The vitamin C content - by capillary electrophoresis on a "Kapel-105M" device, according to the enclosed method;

- $\beta$-carotene - by the photometric method on a spectrophotometer "SF-104" according to GOST 8756.22-80 [10];

- Qualitative polysaccharides DFCs composition studies were carried out by IR spectroscopy on an IR-FT spectrometer Spectrum Two (Perkin Elmer);

- The total surface area of the crushed raw material obtaining was carried out by the gravimetric method according to GOST 13496.8-72 [11];

- $\mathrm{pH}$ value - with a Mettler Toledo $\mathrm{pH}$ meter;

- Swelling degree was studied according to the method described in [12].For this purpose, $0.2 \mathrm{~g}$ of DFCs were weighed on an analytical balance, put into a graduated vial with $10 \mathrm{~cm} 3$ volume, the volume was brought to the mark with distilled water, and the obtainable mixture was kept for 2 hours at a temperature of 20 and $40^{\circ}$ C.DFCs volume was measured every 10 minutes.Swelling rate was determined using the following formula:

$$
W_{t}=\frac{V}{m}(1)
$$

where $W_{t}$ is swelling rate, $\mathrm{ml} / \mathrm{g}$; 
$\mathrm{V}$ is the sample volume, $\mathrm{ml}$;

$\mathrm{m}$ is the original sample weight, $\mathrm{g}$;

- DFCs water retention property was determined by the centrifugation method: this indicator is equal to waterweigh that is retained by $1 \mathrm{~g}$ of dry fiber [13];

- DFCs sorption property in relation to lead $\left(\mathrm{Pb}^{2+}\right)$ and nickel $\left(\mathrm{Ni}^{2+}\right)$ ions was determined by complexometric titration [14];

- The number of bifidobacteria in dairy products was determined according to GOST 33491-2015 [16].

- The biotechnological potential was assessed by milk (fat content 2.5\%) fermentation with the probiotic starter "Bifilakt-Pro" when studied DFCs were added varying their dosage and dispersion. The mixture was preliminarily pasteurized at $85 \pm 2^{\circ} \mathrm{C}$ for 15 minutes, fermentation was carried out at a temperature of $37 \pm 2^{\circ} \mathrm{C}$. The mathematical planning of the experiment was carried out using the Box-Benkin plan, which is a kind of symmetrical non-compositional plan.lt is convenient in practical application, helps to simplify and reduce the cost of an experiment, since the number of experiments in comparison with a full-factor experiment is reduced.In the process of fermentation, the $\mathrm{pH}$ was monitored and, according to the data obtained, in compliancewith the method [17], the kinetic parameters were determined: maximum acidification velocity $\left(\mathrm{V}_{\max }\right)$ and time to reach $\mathrm{pH}=4.6\left(\mathrm{~T}_{p H}=4.6\right.$, hour) to know the fermentation process ended.After fermentation, the test samples were cooled and stored at a temperature of $4 \pm 2^{\circ} \mathrm{C}$.

All experiments were carried out at least with three times frequency.Statistical processing of the results obtained and the construction of graphical dependencies were carried out according to the recommendations presented in [15] using Statistica 10.0 computer program.A $5 \%(p=0.05)$ confidence interval was used.The obtained data were considered as nonparametric; for this reason, the normal distribution of quantitative traits was not done.The Mann-Whitney test was used to assess the continuous quantities distribution in related groups.

\section{Results and Discussion}

At the first stage, studies were carried out to determine the chemical composition of carrot and pumpkin DFCs obtained in accordance with the above method. The results are shown in Table 1.

From the data obtained (Table 1), it follows that in DFCs, most part (more than $75 \%$ weigh fraction of solid substances) are polysaccharides of DF group, that is confirmed 
TABLE 1: Chemical composition of DFCs

\begin{tabular}{llll} 
Indicators & \multicolumn{2}{l}{ Dietary fiber concentrate } \\
& Carrot & Pumpkin \\
\hline Weigh fraction of solid substances, \% & $96,07 \pm 1,2$ & $96,46 \pm 1,2$ \\
\hline Soluble sugars, \% - total - reducing & $20,7 \pm 0,210,3 \pm 0,1$ & $21,3 \pm 0,210,6 \pm 0,1$ \\
\hline Polysaccharides (Dietary fibers), \% & $74,76 \pm 1,1$ & $75,14 \pm 1,1$ \\
\hline Nitrogen compounds, mg nitrogen/100g & $288 \pm 5$ & $234 \pm 4$ \\
\hline Vitamin C, mg/100g & $3,33 \pm 0,08$ & $4,92 \pm 0,12$ \\
\hline Carotene, $\mathrm{mg} / 100 \mathrm{~g}$ & $42,3 \pm 0,5$ & $47,2 \pm 0,6$
\end{tabular}

by the spectral analysis data presented in Figures 1 and 2.Also, the obtained powders contain simple fermentable carbohydrates and nitrogenous substances, which serve as nutrients for probiotic cultures, there are vitamins and minerals that contribute to their growth and development.Antioxidates, which reduce the negative effect of dissolved oxygen on anaerobic cells, are important components that contribute to bifidobacteria vital activity.In DFCs obtained, $\beta$-carotene and vitamin $C$ areantioxidant active. A number of authors note that the structure of plant tissue itself has a stabilizing effect on probiotics, on the surface of which microbial cells adhesion occurs, and which serves as a protective barrier for various negative factors action [19].

At the next stage of research, using FTIR spectroscopy, the qualitative composition of polysaccharides contained in carrot and pumpkin DFCs has been studied.The research results of the polysaccharide composition are presented in Figures 1 and 2.

FTIR spectroscopy is one of the most promising methods for studying complex multicomponent compositions. It forms the basis of modern organic analysis, including structural analysis, microanalysis and surface analysis.IR spectroscopy is molecularspecific, that allows one to obtain information about functional groups in a molecule, their type, interactions and orientations;selective with respect to isomers, due to the area of "fingerprints"; universal to the requirements for sampling $[19,20]$.

In the obtained IR spectra of DFCs carrot and pumpkin samples: a wide band in 3700$3000 \mathrm{~cm}^{-1}$ area is caused by stretch vibration of $\mathrm{OH}$-groups participating in hydrogen bonds of predominantly intermolecular nature, which is more characteristics of cellulose and hemicellulose; in the range $3000-2800 \mathrm{~cm}^{-1}$ with $2930 \mathrm{~cm}^{-1}$ area peaks, $\mathrm{CH}$ bonds stretch vibration in methylene and methyl groups appear, that is characteristic of cellulose, xylan, and lignin; the absorption band in 1200-950 $\mathrm{cm}^{-1}$ area indicates $\mathrm{OH}$ groups of glucose, which is a part of cellulose and hemicellulose, inulin-like substances and pectin; $1600 \mathrm{~cm}^{-1}$ peak corresponds to lignin. 


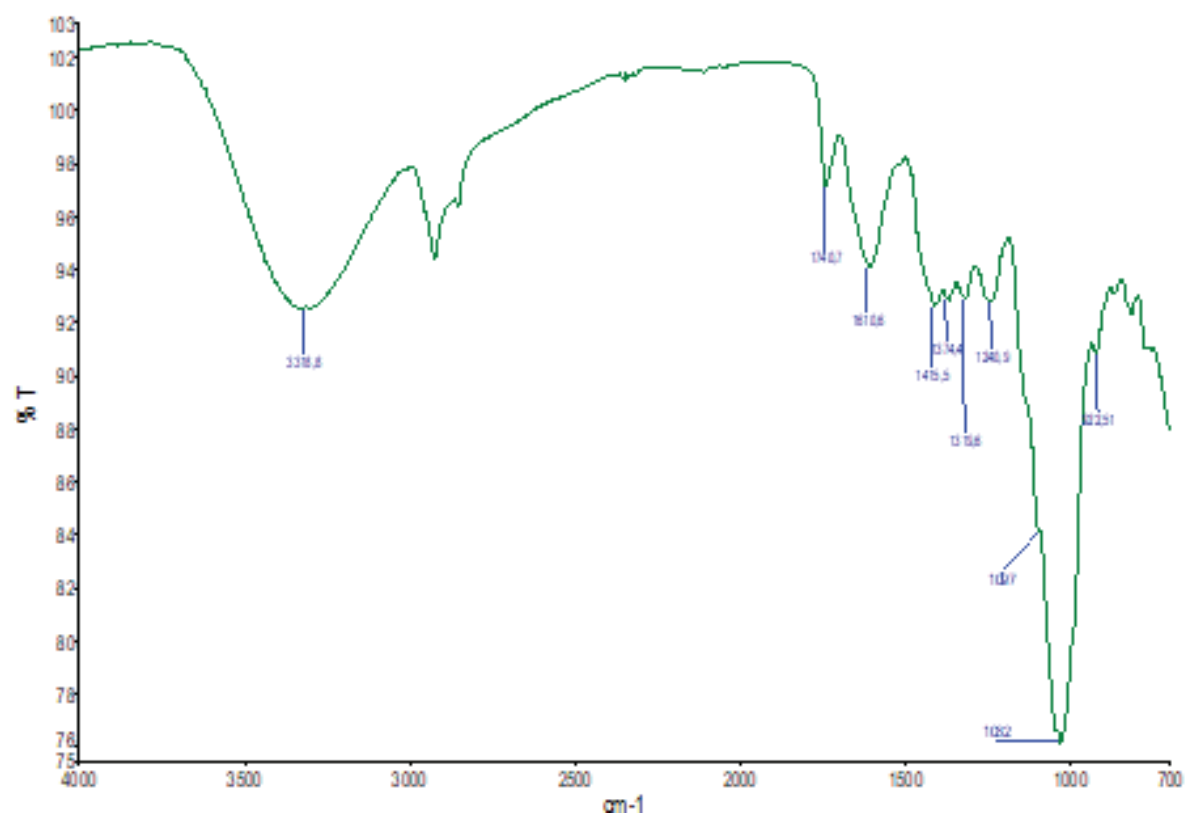

Figure 1: IR spectrum of carrot DFCs.

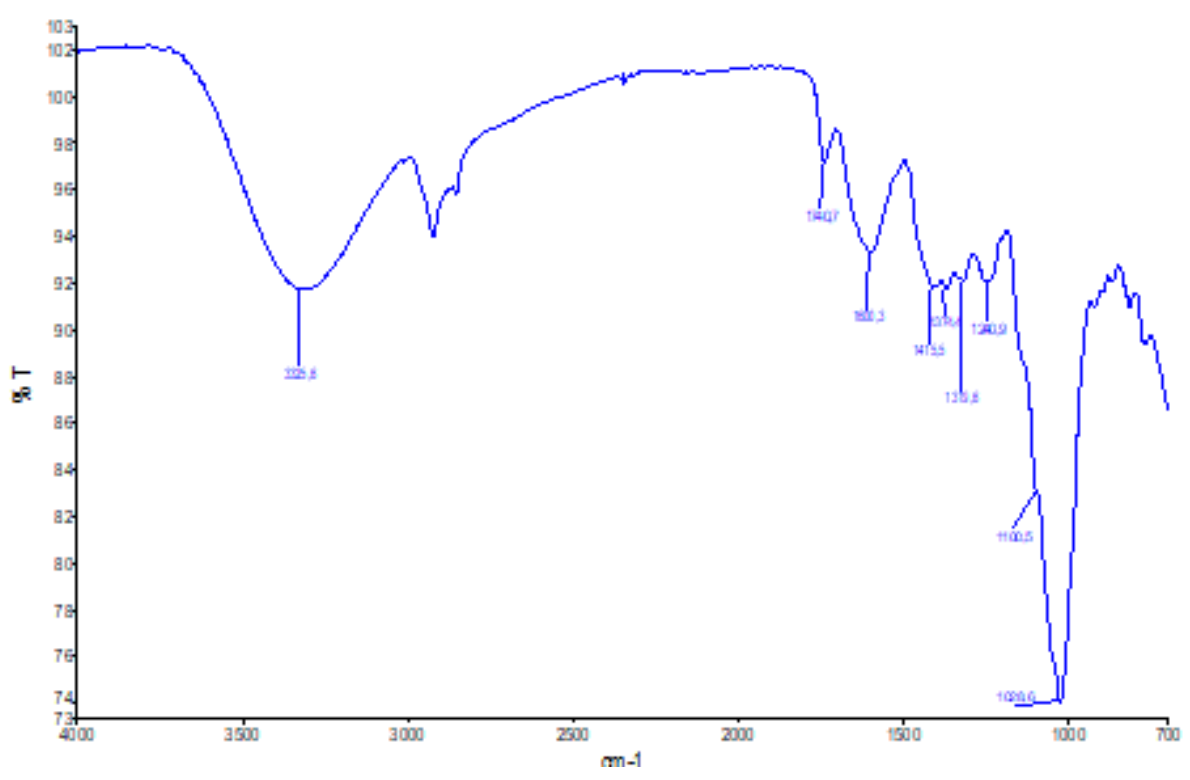

Figure 2: IR spectrum of pumpkin DFCs.

$1740 \mathrm{~cm}^{-1}$ area peakindicates the presence of non-esterified carboxyl groups characteristic of pectin, and1450-1240 $\mathrm{cm}^{-1}$ area peakindicates vibrations, which are characteristic of molecular skeleton.

There are 3 peaks in the samples, indicating the presence of xylose in various forms: vibrations in 1040-1020 cm $\mathrm{cm}^{-1}$ area are characteristic of ether bonds in the cyclic form of xylose, and vibrations in $1100 \mathrm{~cm}^{-1}$ and $1240 \mathrm{~cm}^{-1}$ area are characteristic ofC-C bonds and $\mathrm{OH}$-groups vibrations in the undissociated carboxyl groups of the acyclic xylose form, respectively. 
TABLE 2: DFCs physical and chemical properties.

Indicators
Total surface area, $\mathrm{cm}^{2} / \mathrm{g}$
$\mathrm{pH}$ aqueous solution
Swelling rate $\mathrm{g} / \mathrm{g}$
Swelling time, min
Water-holding capacity, \%
Binding capacity, $\%-\mathrm{Pb}^{2+}-\mathrm{Ni}^{2+}$

\begin{tabular}{l|l}
\multicolumn{2}{l}{ Dietary fiber concentrate } \\
Carrot & Pumpkin \\
$2108 \pm 68$ & $2286 \pm 75$ \\
$6,5 \pm 0,2$ & $6,1 \pm 0,2$ \\
$21,0 \pm 0,1$ & $28,5 \pm 0,15$ \\
$40 \pm 1,2$ & $30 \pm 1,0$ \\
$61,26 \pm 0,9$ & $72,14 \pm 1,1$ \\
$60,2 \pm 1,547,4 \pm 0,7$ & $69,3 \pm 1,153,8 \pm 0,8$
\end{tabular}

The results obtained indicate that the examined samples contain soluble sugars and, to a greater extent, insoluble polysaccharides, which are mainly represented by cellulose, hemicellulose, pectin substances, lignin and, in small amounts, inulin-like polysaccharides.

Table 2 presents the research results of carrot and pumpkin DFCsphysicochemical properties.

As can be seen from the table, DFCs aqueous solutions have a weakly acidic reaction, that makes it possible to add them to milk before pasteurization without the risk of causing casein coagulation during subsequent heat treatment.

The size of DFCs particles is of great importance, since the moisture-absorbing and moisture-holding capacity, the total surface area and DFs fermentation velocity in the colon depend on it.Water binding capacity affects the syneresis of fermented milk, as well as the food gastrointestinal transit.

Swelling time and degree must be taken into account when using DFCs in liquid food products, including dairy products.

From the results presented in table 2 it can be seen that the pumpkin DFCs has a higher moisture-holding capacity and swelling degree with a shorter swelling time.This is due to the quantitative ratio of soluble and insoluble DF in concentrates' composition: for carrot DFCs this ratio is 43:7, and for pumpkin is 39:11.

Many domestic and foreign scientists have proved that DFs, due to its porous-fibrous structure, has the ability to bind and remove heavy metal ions and radionuclides from the human body.As can be seen from the data presented in Table 2, pumpkin DFCs have the highest binding capacity with respect to lead ions, andcarrot DFCs have the highest binding capacity, while this pattern persists with respect to nickel ions.

Currently, the binding capacity value of some polysaccharides used in the food industry are known, and it has been shown that pectin substances can bind up to 


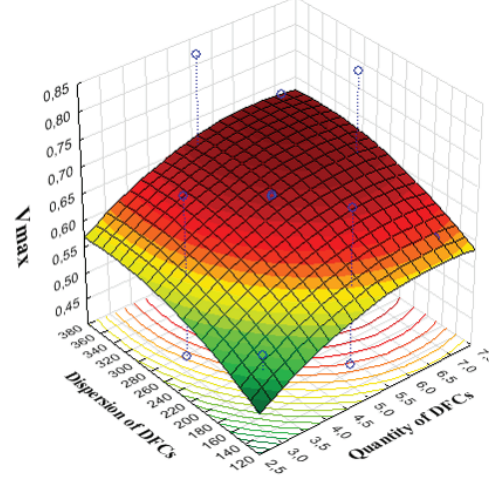

A

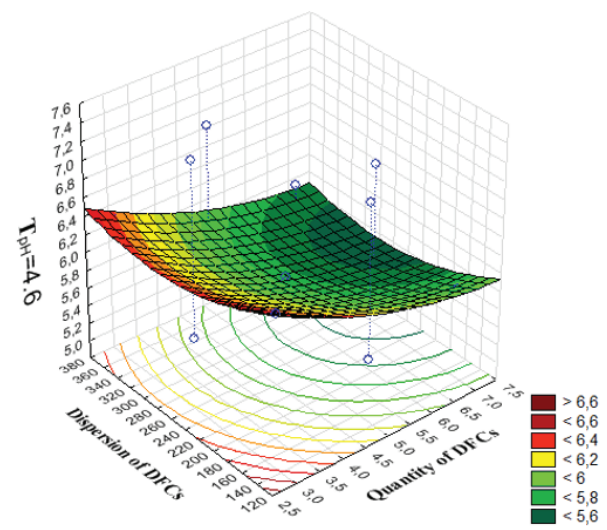

B

Figure 3: Graphs, depicting A-maximumacidification velocity $\left(\mathrm{V}_{\max }\right)$ dependence, B- fermentation time $\left(\mathrm{T}_{p H}=4.6\right)$ on the dosage and particle size of carrot DFCs.

$90 \%$ of lead ions and up to $60 \%$ of nickel ions, these indicators for carrageenan are up to $50 \%$ and up to $40 \%$ respectively.Comparing binding capacity of examined DFCs and polysaccharides, it can be noted that vegetable DFCs are somewhat inferior to pectin substances, but superior to carrageenan.

It is known from the literature that some types of DFs have the ability to accelerate growth and increase the metabolic bifidobacteria activity.This happens due to enzyme content in bifidobacteria that can hydrolyze polysaccharides of cell walls and convert them into easily digestible nutrients.It has also been shown that DFs fermentation velocity will depend on their nature, chemical composition, and particle size [17].

In this regard, it was interesting to study the effect of carrot and pumpkin DFCs on the fermentation kinetics of dairy-vegetable mixtures with the probiotic starter "BifilaktPro", containing lacto-, bifidobacteria and propionic acid microorganisms.Figures 3 and 4 show graphs depictingdependence of maximum reaction velocity $\left(\mathrm{V}_{\max }\right)$ and time for final $\mathrm{pH}$ value to reach $\left(\mathrm{T}_{p H}=4.6\right)$ on type, quantity and dispersion of DFCs injected into milk.

As can be seen from the reported data, maximum acidificationvelocity increases, and fermentation process duration decreases with carrot or pumpkin DFCs concentration increase in the mixture.This is due to an additional quantity of fermentable sugars, which are in herbal supplements and are formed as a result of polysaccharides hydrolysis by probiotic cultures, as well as of nitrogenous substances, vitamins, antioxidants DFCs content, and other growth factors.

The acidificationprocess intensity also directly depends on the size ofDFCs particles. It should be noted that with 200-340 $\mu \mathrm{m}$ dispersion and DFCs increase from 3 to $5 \mathrm{~g} / 200$ $\mathrm{ml}$, the acidificationtime is reduced from 8 to 6 hours. 


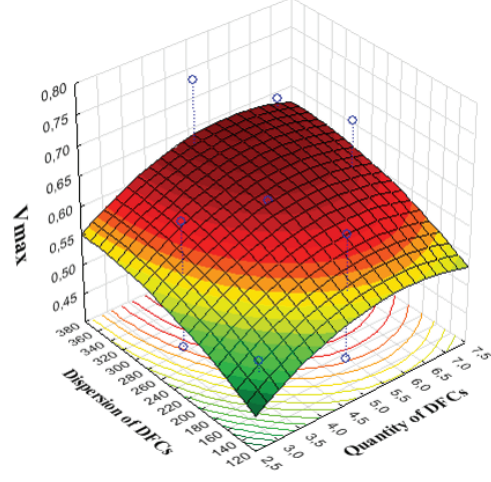

$\mathbf{A}$

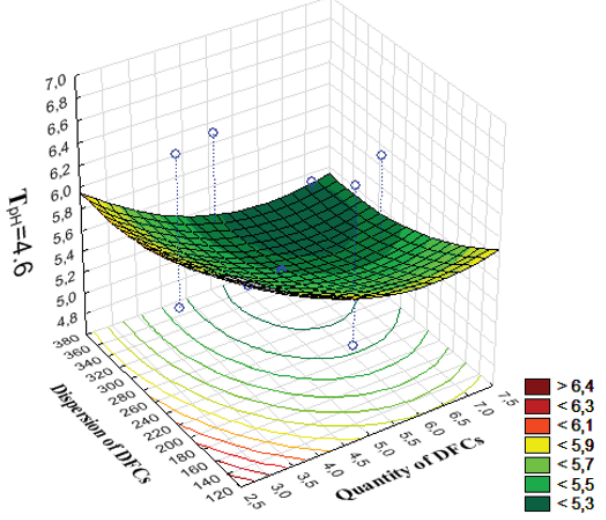

B

Figure 4: Graphs, depicting A-maximum acidificationvelocity $\left(\mathrm{V}_{\max }\right)$ dependence, B- fermentation time $\left(\mathrm{T}_{p H}=4.6\right)$ on the dosage and particle size of pumpkin DFCs.

At the same time, it was found that with DFCs increase over $5 \mathrm{~g} / 200 \mathrm{ml}$ and particle sizes over $280 \mu \mathrm{m}$, the degustation evaluation of fermented samples decreases.

From Figures $3 \mathrm{~A}$ and $4 \mathrm{~A}$ it follows that when DFCs are added to milk in a quantity of $5 \mathrm{~g} / 200 \mathrm{ml}$ with particle sizes from $200 \mu \mathrm{m}$ for carrot and from $220 \mu \mathrm{m}$ for pumpkin, a sufficiently high reaction velocity $\vee \max \geq 0.65$ is achieved [17], while the investigated factors values do not go beyond the limitations associated with the organoleptic properties of fermentation products.

Based on complex experimental data obtained, it was proposed to use carrot and pumpkin DFCs in the production of probiotic fermented milk drinks in aquantity of $2.5 \%$ with $250 \pm 30 \mu \mathrm{m}$ dispersion, which allows to ensure milk base reaction duration at $37 \pm 2^{\circ} \mathrm{C}$ for 6 hours and obtainproduct with good taste and functional properties. Taking into account the recommendations developed, drink samples have been prepared, their quality and safety indicatorshave been determined, they fully conformedto the established requirements.

To confirm the probiotic properties in the samples, we have determined the number of bifidobacteria, that after 15 days storage at a temperature of $4-6^{\circ} \mathrm{C}$ was at least $6 \bullet 10^{10} \mathrm{CFU} / \mathrm{g}$ for fermented milk product with carrot DFCs addition at least $3 \bullet 10^{9} \mathrm{CFU} / \mathrm{g}$ for fermented milk product enriched with pumpkin DFCs.The results obtained are consistent with the data of this work[21], which notes that cell walls fragments, as well as lyophilized fruit and vegetable pieces, promote better growth, reproduction and probiotic cultures survival in fermented dairy production. This is explained by selfimmobilization microorganisms-probiotics cells effect on plant fibers, as a result their resistance to various unfavorable factors increases. 


\section{Conclusions}

As a result of the research, the chemical composition, spectral characteristics, physicochemical properties andbiotechnological potential of carrot and pumpkin DFCs obtained from juice production SRRhave been studied. It has been established that while putting these functional ingredients into the milk base it makes possible to intensify the fermentation process with probiotic cultures and to ensure the stability of product functional properties during cold storage.The data obtained has formed the basis for formulations development and biotechnology of probiotic dairy products with high taste qualities and a wide range of physiological activity.

\section{References}

[1] Dhingra D, Michael M, Rajput H, Patil R. Dietary fibre in foods: A review. Journal of food science and technology. 2012. 49 (3). 255-266. 10.1007/s13197-011-0365-5.

[2] Rodríguez R, Jiménez A, Fernández-Bolaños J, Guillen R, Heredia A. Dietary fibre from vegetable products as source of functional ingredients. Trends in Food Science \& Technology. 2006;17(1):3-15.

[3] Schieber A, Stintzing F, Carle R. By-products of plant food processing as a source of functional compounds - recent developments. Trends in Food Science \& Technology. 2001;12:401-413.

[4] Santo APE, Cartolano NS, Silva TF et al. Fibers from fruit by-products enhance probiotic viability and fatty acid profile and increase CLA content in yoghurts. International Journal of Food Microbiology.2012;154(3):135-144.

[5] Puvanenthiran A, Stevovitch-Rykner C, McCann TH, Day L. Synergistic effect of milk solids and carrot cell wall particles on the rheology and texture of yoghurt gels. Food Research International. 2014;62:701-708.

[6] Sendra EP, Fayos SY, Lario JF-L, Estrella S-B, Pérez-Alvarez JA. Incorporation of citrus fibers in fermented milk containing probiotic bacteria. International Journal of Food Microbiology. 2008;21(1):13-21.

[7] de Albuquerque MAC, Bedani R, LeBlanc JG, Saad SAI. Passion fruit by-product and fructooligosaccharides stimulate the growth and folate production by starter and probiotic cultures in fermented soymilk. International Journal of Food Microbiology. 2019;292:126-136.

[8] Ermakov Al. Methods of biochemical research of plants. Leningrad: Kolos; 1972. 
[9] GOST standard13496.4-93. Feed, mixed feed, feed raw materials. Methods for determining nitrogen and crude protein content. Moscow: Standartinform; 2011.

[10] GOST standard 8756.22-80. Fruit and vegetable processing products. Method for the determination of carotene. Moscow: Standartinform; 2010.

[11] Standartinform M. GOST standard 13496.8-72. Mixed fodder. Methods for determining the size of grinding and the content of non-ground seeds of cultivated and wild plants. Moscow: Standartinform; 2011.

[12] Halagur B, Sowbhagya P, Suma F, Mahadevamma S, Rudrapatnam N, Tharanathan. Spent residue from cumin - a potential source of dietary fiber. Food Chemistry.2007;104(3):1220-1225.

[13] Grek E, Krasulya E. Investigation of the influence of dietary fibers on the forms of moisture binding in mixtures with whey. Maisto Chemija Ir Technologija.2013;1:15-21.

[14] Umland F, Ansen AY, Tirig D. Complex compounds in analytical chemistry. Moscow: Mir; 1975.

[15] Standartinform M. GOST standard 33491-2015. Dairy products enriched with Bifidobacterium bifidum. Technical conditions. Moscow: Standartinform; 2009.

[16] Kristo E, Biliaderis CG, Tzanetakis N. Modelling of rheological, microbiological and acidification properties of a fermented milk product containing a probiotic strain of Lactobacillus paracasei.International Dairy Journal.2003;13:517-528.

[17] UnguryanuTN, Grzhibovskij AM. Brief recommendations for describing, statistical analysis, and presenting data in scientific publications. Human Ecology. 2011;5:5560.

[18] Mohammadi R, SohrabvandiS, Mortazavian MA. The starter culture characteristics of probiotic microorganisms in fermented milks. Engineering in Life Sciences. 2015;12:399-409.

[19] Mengmei M, Taihua M. Effects of extraction methods and particle size distribution on the structural, physicochemical, and functional properties of dietary fiber from deoiled cumin. Food Chemistry. 2016;194:237-246.

[20] Huang Z-L, Liang Z-Y, Li G-J, Hong H. Response surface methodology to extraction of dioscoreae polysaccharides and the effects on rat's bone quality. Carbohydrate Polymers. 2011;83(1):32-37.

[21] Rubel IA, Prerez EE, Genovese DB, Manrique GD. In vitro prebiotic activity of inulin-rich carbohydrates extracted from Jerusalem artichoke (Helianthus tuberosus L.) tubers at different storage times by Lactobacillus paracasei. Food Research International. 2014;62:59-65. 